\title{
Perception and Use of PowerPoint at Library Instruction Conferences
}

\section{David J. Brier and Vickery Kaye Lebbin}

\author{
David J. Brier and Vickery Kaye \\ Lebbin are social sciences librarians \\ at Hamilton Library, University of \\ Hawaii at Manoa. Submitted for \\ review December 9, 2007; revised and \\ accepted for publication April 18, 2008.
}

Reference \& User Services Quarterly, vol. 48, no. 4, pp. 352-361

(c) 2009 American Library Association. All rights reserved.

Permission granted to reproduce for nonprofit, educational use.
This article examines Microsoft PowerPoint use at library conferences. Through a survey of two hundred librarians, the first part explores librarians' perceptions of PowerPoint use at library instruction conferences. Through a content analysis of sixty-seven PowerPoint presentations, the second part of the paper describes the design strategies and techniques used by instruction librarians to share their knowledge and work with colleagues at conferences. Based on the results of the survey, content analysis, and the advice of presentation consultants, the final section of the paper recommends ways to improve PowerPoint presentations.

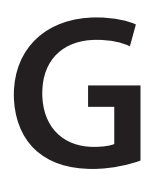
iven the prevalence of Microsoft PowerPoint use at library conferences, it is surprising how few librarians have studied it. ${ }^{1}$ The literature produced by librarians on PowerPoint is scant and tends to either lament its use or suggest strategies to communicate effectively with it. ${ }^{2}$ In this paper, we compare what librarians say they want and need as viewers of PowerPoint with what the producers of PowerPoint are delivering. We study the information needs and interests of both the producers and consumers of PowerPoint. The focus is not on what presenters are saying with PowerPoint but how they are saying it and why they are using it. Our goal is not to provide librarians with a detailed technical blueprint or a buffet of tools and techniques to make knock-'em-dead PowerPoint programs, but rather a set of ideas to be discussed and an overall direction and strategy for crafting more effective PowerPoint presentations. We hope the article will help you (re)think the way you create and view PowerPoint presentations.

While the analysis centers on instruction librarians and conferences, the same issues resonate at other library conferences, internal library meetings, and, to some extent, when teaching students with PowerPoint. After viewing hundreds of PowerPoint presentations at a variety of local, national, and international library conferences, we have concluded that although no one single design style can capture the variety of individual presentations, the recurrence of particular design elements happens so frequently that we can characterize PowerPoint presentations at library conferences as a whole regardless of the type, specialty, or place of librarianship. Thus the paper has applicability beyond instruction librarians that work in academic libraries.

As part of their professional responsibilities, academic librarians are encouraged to present at professional 
conferences. For many of these librarians, PowerPoint is the preferred method of communicating their knowledge and work to colleagues at conferences. This article is written for these librarianslibrarians who desire to have more insight into how PowerPoint is being used at library conferences and what their audiences want and need from PowerPoint presentations. The article has value for librarians new to the conference scene as well as seasoned veterans hoping to develop more effective presentations using PowerPoint.

\section{LITERATURE REVIEW}

The seminal criticism of PowerPoint is contained in Yale University professor emeritus Edward Tufte's The Cognitive Style of PowerPoint. Since its publication in 2003, this influential twenty-seven page polemic is referred to regularly by fans and detractors. In Tufte's argument, the adoption of PowerPoint unavoidably brings with it problems and habits of thinking. Tufte calls attention to the detrimental influence that PowerPoint has on presentations:

Foreshortening of evidence and thought, low spatial resolution, an intensely hierarchical single-path structure as the model for organizing every type of content, breaking up narratives and data into slides and minimal fragments, rapid temporal sequencing of thin information rather than focused spatial analysis, conspicuous chartjunk and PP Phluff, branding of slides with logotypes, a preoccupation with format not content, incompetent designs for data graphics and tables, and a smirky commercialism that turns information into a sales pitch and presenters into marketers. ${ }^{3}$

Tufte does not stop here. Drawing on Shaw, Brown, and Bomiley's paper on business planning in the Harvard Business Review, Tufte finds fault with the use of the bulleted lists of brief phrases that permeate PowerPoint presentations. ${ }^{4}$ In effect, bulleted lists leave out important information and critical assumptions such as the who, what, when, and where needed for audiences to understand and evaluate an argument. Bulleted lists contribute to oversimplification, superficial reasoning, imprecise logic, and, at times, misleading conclusions. This point is particularly important for speakers at library conferences because the bulleted list is the most widely used format in library conference presentations.
A second, somewhat weaker, version of the argument holds that PowerPoint is strongly compatible with, but does not strictly require a particular design and cognitive style. Catherine Adams, a faculty member in the Department of Computing Science at Grant MacEwan College, for example, describes how PowerPoint invites or softly determines rather than requires the user in default design to create presentations in bulleted format. ${ }^{5}$

A third and alternative view to Tufte's argument can be found in Harvard University psychologist Stephen M. Kosslyn's Clear and to the Point: 8 Psychological Principles for Compelling PowerPoint Presentations. Kosslyn asserts that there is nothing in PowerPoint requiring the bullet-point mindset and cognitive style that Tufte describes. ${ }^{6}$ In contrast to the "software made me do it" camp, Kosslyn stresses the latitude and potential in PowerPoint to produce presentations that inform, motivate, and inspire audiences. Kosslyn argues it is the producer's knowledge, skills, and finesse with PowerPoint that ultimately determine the quality and ensuing cognitive style of presentation. Unable to settle controversies over this matter here, we merely point to what we consider to be a major tension in the literature.

\section{METHOD}

Both quantitative and qualitative methods were used in this research. The 2006, LOEX and LOEXof-the-West (LOTW) conferences were the subjects of the study. The key conferences on information literacy in the United States, the two events are similar in format and size. A survey provided perspectives on attendees' perceptions of PowerPoint use while a content analysis of PowerPoint slides offered data on how presenters used PowerPoint.

\section{Survey}

To assess how LOEX and LOTW attendees think about and use PowerPoint at conferences, we developed a structured questionnaire of twenty-eight open and closed questions. Drawing on a survey by PowerPoint presentation consultant Dave Paradi, one set of questions asked respondents to identify the annoying elements of bad PowerPoint presentations. ${ }^{7}$ Another set of questions uses the VARK (visual, aural, read/write, and kinesthetic sensory modalities) inventory to identify respondent's primary learning styles. ${ }^{8}$ We e-mailed an invitation with a description of the study and Internet address of the survey to all 438 attendees of the 2006 LOEX and LOTW conferences. Twentynine e-mails bounced back because of unknown- 
addresses errors and automated-absence replies. We sent a follow-up e-mail several days later to the 409 attendees with valid e-mail addresses. The survey was open for one week. Participation was voluntary and confidential. A total of 200 attendees (49 percent) began the survey with an attrition of 19 , resulting in 181 (44 percent) completing the survey.

\section{Content Analysis}

The content analysis focused on the PowerPoint presentations from conference breakout sessions. LOEX had 30 presentations (60 minutes each) and LOTW had 40 presentations (45 minutes each). Of the 70 total presentations, we were able to retrieve and analyze 67 (about 95 percent) of the PowerPoint programs used. In total, we examined 1,833 slides. Of those, 845 slides ( 29 presentations) were from LOEX and 988 slides (38 presentations) were from LOTW. Presentations were analyzed and coded at the slide level for word count, bullet points, and visual elements. Slide color and genre were examined at the presentation level.

\section{SURVEY FINDINGS}

A summary of the responses, grouped into five topics, follows.

\section{Audience Preference for PowerPoint Use}

Given the popular idea that audiences do not want presenters to use PowerPoint, one of the noteworthy findings of this survey is that 73 percent of respondents indicated they usually, frequently, or always prefer speakers to use PowerPoint. When asked to explain this in an open-ended question, the following reasons were provided for this preference: it visually reinforces and supplements the speaker's verbal message, it outlines and organizes the presentation, and it aids notetaking. When asked why they prefer presenters not to use PowerPoint, the negative reasons listed included overuse, misuse, and inflexibility.

\section{Presenter Preference for PowerPoint}

The power in PowerPoint comes from the way it functions as a given for both presenter and audience. Earlier in this paper we asserted that PowerPoint is the preferred method of communicating knowledge at professional library conferences. When asked if they have ever presented at a library conference, about 80 percent of respondents said yes. Of those, about 92 percent have used PowerPoint at their presentations.

Respondents were further asked why they used or did not use PowerPoint. For those that indicated they used PowerPoint, the following three reasons appeared regularly in their descriptions: it organizes content, adds visual impact, and is expected by colleagues. For those respondents that indicated they did not use PowerPoint the following general reasons were provided:

- It creates a distance between the speaker and the audience (or other speakers if one is on a panel) and therefore inhibits discussion.

- It disrupts the natural flow of conversations.

- It restricts the speaker's physical mobility to move throughout the crowd.

- It is not as attractive as using Web-based alternatives or live Web demonstrations.

- It would add nothing to the presentation's content.

- It is so common that one's presentation is unmemorable.

\section{Peer Pressure to Use PowerPoint}

Half of respondents said that their colleagues would judge them as unprofessional if they did not use PowerPoint. On the flip side, 85 percent of the respondents revealed that they seldom or never believe a presenter is unprofessional if they did not use PowerPoint.

\section{Characteristics of Bad PowerPoint Presentations}

Respondents selected the top five characteristics of bad PowerPoint presentations (see table 1):

- Speaker reads the slides

- Overuse of text

- Full sentences and paragraphs instead of bullet points

- Text too small to read

- Slides hard to see because of color choice

Respondents were then given the opportunity with an open-ended question to further describe the characteristics of bad PowerPoint presentations. Nine general complaints emerged:

- Slide-centered presentations: speakers either can't go beyond the slide content or focus on the slides rather than the audience, resulting in the feeling that the slides drive the presentation rather than the speaker. 
Table 1. Characteristics of Bad PowerPoint Presentations $(n=200)$

\begin{tabular}{|c|c|c|c|c|}
\hline & 1st choice & 2nd choice & 3rd choice & Overall \\
\hline Speaker reads the slides & $106(53.0 \%)$ & $25(12.5 \%)$ & $20(10.0 \%)$ & $151(25.2 \%)$ \\
\hline Overuse of text & $23(11.5 \%)$ & $53(26.5 \%)$ & $29(14.5 \%)$ & $105(17.5 \%)$ \\
\hline Text so small I couldn't read it & $17(8.5 \%)$ & $36(18.0 \%)$ & $29(14.5 \%)$ & $82(13.7 \%)$ \\
\hline $\begin{array}{l}\text { Full sentences and paragraphs instead } \\
\text { of bullet points }\end{array}$ & $19(9.5 \%)$ & $39(19.5 \%)$ & $37(18.5 \%)$ & $95(15.8 \%)$ \\
\hline $\begin{array}{l}\text { Bullet points instead of full sentences } \\
\text { and paragraphs }\end{array}$ & $1(0.5 \%)$ & $4(2.0 \%)$ & $2(1.0 \%)$ & $7(1.2 \%)$ \\
\hline Slides hard to see because of color choice & $12(6.0 \%)$ & $16(8.0 \%)$ & $33(16.5 \%)$ & $61(10.1 \%)$ \\
\hline Moving/flying text or graphics & $7(3.5 \%)$ & $14(7.0 \%)$ & $21(10.5 \%)$ & $42(7.0 \%)$ \\
\hline Annoying use of sounds & $7(3.5 \%)$ & $6(3.0 \%)$ & $14(7.0 \%)$ & $27(4.5 \%)$ \\
\hline Overly complex diagrams or charts & $6(3.0 \%)$ & $6(3.0 \%)$ & $11(5.5 \%)$ & $23(3.8 \%)$ \\
\hline Slides containing more than one point & $2(1.0 \%)$ & $1(0.5 \%)$ & $4(2.0 \%)$ & $7(1.2 \%)$ \\
\hline
\end{tabular}

- Too many slides: speakers either have a slide for everything or skip, zoom through, or don't finish as a consequence of having too many slides, usually trying to say too much in too short a time.

- Lack of visuals and poor graphic design: presentations are either overloaded with text slides or suffer from problems with functional and aesthetic design-usually graphics that fail to intrigue, entertain, captivate, or inspire.

- Disconnect between slides and talk: slide content differs from the speaker's verbal messages.

- Inadequate and wasteful handouts: handouts either simply duplicate PowerPoint presentations or fail to summarize the important points in complete sentences, usually resulting in wasted paper.

- Audiovisual problems: speakers are unfamiliar with the presentation technology or audiovisual equipment malfunctions.

- Undesirable presentation environments: rooms that suffer from poor lighting, excessive glare, or inadequate sightlines.

- Unrehearsed presentations: speakers don't appear to have carefully planned or practiced their presentation.

- Spelling errors: spelling mistakes distract from the presentation and the speaker's credibility.

\section{Learning Style}

The survey results indicate that 76 percent of the respondents learn best through a combination of visuals, sound, and touch. When asked to describe their primary learning style, seventy-five (38 percent) indicated visual, forty-eight (24 percent) indicated read/write, forty (20 percent) indicated tactile/kinesthetic, and thirty-five (18 percent) indicated auditory.

\section{CONTENT ANALYSIS FINDINGS}

Of the sixty-seven presentations, the smallest number of slides was nine at LOTW and the largest number was eighty-three at LOEX. The average number of slides at LOEX was twenty-nine, or about one slide for every two minutes of the sixty-minute presentations. At LOTW, the average number of slides was twenty-six, or slightly less than one slide for every two minutes of the fortyfive-minute presentations.

\section{Slide Word Count and Bullet Points}

As respondents pointed out, PowerPoint slides often have too much text. A total of 731 out of 845 LOEX slides (87 percent) contained text - a total of 21,640 words. Of these 731 slides, 460 were text-only - a total of 17,825 words. A total of 904 out of 988 LOTW slides (93 percent) contained text - a total of 26,305 words. Of these 904 slides, 575 were text-only-a total of 21,244 words. The average number of words on text-only slides was 39 for LOEX and 37 for LOTW.

Respondents rated "full sentences and paragraphs instead of bullet points" the third most 
annoying characteristic of bad PowerPoint presentations. To see how this fared in practice, the content analysis examined the use of bullet points. Two-thirds of the LOEX text slides and 77 percent of the LOTW text slides included bullets. These findings suggest that approximately 25 percent of the text slides for both events used full sentences and paragraphs.

\section{Slide Visual Elements}

All slides were coded for the types of elements (clipart, diagram, form, graph, photograph, screenshot, and text) they contained. Elements were not counted if they were incorporated into the slide template, which appeared the same throughout the presentation. Video and audio were calculated but insignificant. LOTW had only one presentation that used audio and one presentation that used video. None of the LOEX presentations incorporated audio or video.

Text was the slide element most used in the presentations-at least four times more than any other element. At LOEX, 62 slides (7 percent) included clipart, 21 (2 percent) included diagrams, 8 (1 percent) included forms, 45 (5 percent) included graphs, 85 (10 percent) included photographs, 186 (22 percent) included screenshots, and 731 (87 percent) included text. At LOTW, 100 slides (10 percent) included clipart, 29 (3 percent) included diagrams, 1 (0 percent) included forms, 50 (5 percent) included graphs, 127 (13 percent) included photographs, 120 (12 percent) included screenshots, and 904 (91 percent) included text.

Calculations were also performed for those slides that contained only text and no other element. LOEX had 460 slides (54 percent) and LOTW had 575 slides (58 percent) with only text.

\section{Presentation Color}

The most frequent color combination, used by 25 presentations ( 37 percent), was a white background with black text. Using Pardi's Color Contrast Calculator, based on international standards developed by the World Wide Web Consortium
(W3C), presentation background and text colors were calculated for color contrast. ${ }^{9}$ Fourteen presentations ( 21 percent) failed the color contrast test (see table 2).

\section{Presentation Elements of Genre}

PowerPoint presentations at library instruction conferences are, in a sense, a genre. They have particular, distinctive, and predictable elements:

- Show and tell: an illustration or demonstration, usually screen shots or a photo, of a resource or service. The show-and-tell technique is the process of showing the audience the resource or service and telling them about it. This element was used in 34 percent of the programs.

- Testimonial: a written or spoken statement from a patron that (1) establishes a sense of urgency
Table 2. Slide Colors

\begin{tabular}{llllll}
\hline Background/Text & LOEX & LOTW & Total & $\%$ & $\begin{array}{l}\text { Pass } \\
\text { or fail } \\
\text { contrast } \\
\text { test? }\end{array}$ \\
White / Black & 13 & 12 & 25 & 37 & Pass \\
Dark Blue / White & 3 & 2 & 5 & 7 & Pass \\
Tan / Black & 2 & 2 & 4 & 6 & Pass \\
Light Blue / Black & 1 & 2 & 3 & 4 & Pass \\
Black / White & 2 & 1 & 3 & 4 & Pass \\
White / Blue & 2 & 1 & 3 & 4 & Pass \\
Gray / Black & 2 & 1 & 3 & 4 & Pass \\
Blue / White & 0 & 2 & 2 & 3 & Fail \\
Blue / Black & 0 & 2 & 2 & 3 & Fail \\
Dark Blue / Yellow & 1 & 1 & 2 & 3 & Pass \\
Light Blue / White & 0 & 2 & 2 & 3 & Fail \\
Red / White & 0 & 2 & 2 & 3 & Pass \\
Tan / Brown & 1 & 1 & 2 & 3 & Pass \\
Gold / Black & 1 & 1 & 2 & 3 & Fail \\
Yellow / Black & 0 & 1 & 1 & 1 & Pass \\
Brown / Tan & 0 & 1 & 1 & 1 & Fail \\
Dark Blue / Tan & 0 & 1 & 1 & 1 & Pass \\
Dark Blue / Gray & 1 & 0 & 1 & 1 & Fail \\
Gray / Gray & 0 & 1 & 1 & 1 & Fail \\
Green / Gray & 0 & 1 & 1 & 1 & Fail \\
Yellow / Gray & 0 & 1 & 1 & 1 & Fail \\
\hline & & & & & \\
\hline
\end{tabular}


or need for the presenter's resource or service, usually through the description of a problem the patron is experiencing; or (2) articulates the solution or reduction of the patron's problem through the presenter's resource or service. The primary function of the testimonial is to make the presenter's problem-and-solution claim believable. This element was used in 28 percent of the programs.

- Supporting quote: a quote from an outside source or expert that supports the presenter's position. Generally, the quote is nothing more than an opinion. Typically, the opinion comes from an expert, famous historic figure, or respected current practitioner. By tapping expert opinion to advocate the presenter's position, the credibility of the expert becomes a substitute for the presenter's. A supporting quote was used in 25 percent of the programs.

- Association position: a professional association's official stance stated in the form of a goal, standard, or committee decision. The presenter uses the association's position to authorize or legitimize their resource or service. This element was used in 22 percent of the programs.

- Patron portrait: a list or photo describing demographic, psychological, socioeconomic, or lifestyle characteristics of a group of patrons. The characteristics, attitudes, and opinions of the patron group are represented in monolithic terms and reduced to a few oversimplified, stereotypical traits. Patron portraits were used in 19 percent of the programs.

- Lessons learned: a collection of important discoveries after instituting a resource or service. This style of slide functions as "the moral of the story." Lessons learned were included in 12 percent of the programs.

- Survey says: a summary of survey findings. The survey is used to reinforce a resource or service's validity. This element was included in 12 percent of the programs.

\section{DISCUSSION AND IMPLICATIONS}

The survey and content analysis offer guidance on how to improve PowerPoint presentations.

\section{Peer Pressure}

Although respondents indicated that they prefer presenters to use PowerPoint, presenters tend to overestimate the extent to which their colleagues will judge them as unprofessional if they do not use PowerPoint.

\section{Learning Style}

The results of this study indicate that there is a mismatch between the typical PowerPoint slide primarily composed of text and the learning needs of the plurality of respondents. By loading their slides with text, presenters are catering to the minority of read/write learners. However, because the text slides consist primarily of bulleted lists of brief phrases, even the read/write learner's needs are marginalized by an instructional design that features an assemblage of incomplete sentences. Tufte argues that "bullet outlines can make us stupid."10 Shaw, Brown, and Bromiley put it this way:

Bullet lists encourage us to be intellectually lazy in three specific, and related ways. Bullet lists are typically too generic; that is, they offer a series of things to do that could apply to any business.... Bullets leave critical relationships unspecified. ... Bullets leave critical assumptions about how the business works unstated. ${ }^{11}$

Although Shaw, Brown, and Bromiley were examining slides in business presentations, their findings and conclusions have applicability in the library profession. Consider, for example, the following bullet point from a LOEX presentation:

\section{- Digital games are fun}

The generic information in this bullet point leaves out more than it provides. Who (and who does not) think digital games are fun? Are all games equally fun? Is fun enough of an incentive for students to play library-related digital games (or does the game have to be assigned)? In terms of getting the students to play, to what extent is it more important for the game to be relevant to coursework than fun? To what extent is the perspective of those who find digital games silly or boring integrated into these slides? Does the fun and engagement of games result in enhanced students or citizens? Although the speaker may address these questions within their talk, to what extent do the words on this PowerPoint slide supplement, extend, or reinforce the speaker's message? In short, they do not. So, who is best served by this type of PowerPoint design? The primary beneficiary of this slide, like hundreds of others we examined, is the presenter. The slide's primary function here is to help the presenter remember what to say. The slide is not designed to help the read/write learners or any of the other learners better grasp the message. As Tufte writes, the "convenience of the speaker can be costly to both content and audience."12 
Read/write learners, as well as all the other types of learners, would be better served by a speaker that either foregoes PowerPoint here or by a PowerPoint slide that provides visuals and sounds—charts, diagrams, illustrations, photos, videos, or podcasts. This slide should be accompanied by a handout that contains, according to Tufte, "sentences with subjects and verbs" and a narrative. ${ }^{13}$

In terms of instructional design, few, if any, learners are best served by the dominant practices in PowerPoint design at library conferences. According to the VARK theory of learning styles, one's learning style is primarily either visual, auditory, touch, or read/write. In other words, a selfidentified read/write learner is not only able to learn through text. A read/write learner can learn through visuals and sound during the presentation and read text in a handout after the presentation. Similarly, the visual and auditory learners can learn through graphics and sound during the presentation and through text in the handout after the presentation. Presentations should be engaging enough to motivate all types of learners to read the handout after the presentation

\section{How Many Slides}

Like many aspects of effective PowerPoint design, there is no general agreement on the optimal number of slides. To illustrate, Harvard University's John F. Kennedy School of Government's Multimedia Services recommends not covering more than three slides per minute. ${ }^{14}$ Using this guideline, LOTW presenters could have showed up to 135 slides and LOEX presenters a whopping 180 slides. Simultaneously, and in stark contrast, the speaker guide for a technology conference, Linux Bangalore, encourages presenters to "on an average, assume 5 minutes per slide. A 30 minute talk would have no more than 6-10 slides." ${ }^{15}$ From this perspective, LOEX programs should have limited their program to a maximum of ten slides and LOTW presenters to about seven or eight slides. Meanwhile at Dickinson College, Technology Services points out that "a good rule of thumb is one slide per minute." ${ }^{16}$ Through this lens, LOEX and LOTW speakers used too many slides. Finally, Princeton University's Library Excellence Toolkit on Presentation Skills recommends one or two slides per minute. ${ }^{17}$ Following this general rule of thumb, LOEX and LOTW speakers had just about the right number of slides.

The slide-count rules listed above are most appropriate for text slides. Presenters preparing text slides should heed the "too many slides" complaint voiced by respondents. However, presenters showing slides that largely feature audio and visuals will not find the slide-count rules useful.

\section{Words Per Slide}

Presentation consultants differ on the optimal number of words or the word limit per slide. To illustrate, Seth Godin argues that you should have "no more than six words on a slide. EVER." 18 Meanwhile over at Corbin Ball Associates, presenters are counseled not to exceed fifteen words on any slide. ${ }^{19}$

The top four characteristics of bad PowerPoint presentations identified by respondents have to do with the use of text ("speaker reads the slides," "overuse of text," "full sentences and paragraphs instead of bullet points," and "text so small I couldn't read it"). Generally, the more text-heavy a slide, the more likely the audience will be annoyed with the presentation.

\section{Slide Color}

Color selection is particularly useful in our analysis because respondents ranked low color contrast as one of the most annoying elements of bad PowerPoint presentations. Thus the examination of contrast between the colors chosen for the background and the text or graphics is important because it affects readability. The results from the color contrast calculator test indicate that, in general, presenters did a good job of selecting colors that had enough contrast. However, 21 percent of the presentations suffered from poor contrast. These presentations are likely to have contributed to the "slides hard to see because of color choice" problem ranked by respondents as the fifth most annoying element of bad PowerPoint presentations. Specific recommendations for color selection are provided by a couple of presentation consultants. According to PowerPoint presentation consultant Geetesh Bajaj, most people's favorite presentation background color is blue. ${ }^{20}$ Eighteen presentations ( 27 percent) used blue as a background. Bajaj recommends using dark blue backgrounds with white or yellow text. Seven presentations (10 percent) used a dark blue background with white or yellow text. When selecting dark backgrounds with light text, Paradi suggests a dark blue (navy shade) or dark purple with white or yellow text. For light backgrounds with dark text, Paradi advises a warm beige with dark blue, black, or dark purple text. ${ }^{21}$ Two presentations (6 percent) used a tan background with black text. 


\section{Genre}

In effect, the recurring elements used in PowerPoint presentations at library conferences provide audiences with a soft infomercial (establishing a problem or need, solution to the problem or need, product demo, testimonial endorsing the product, quotes from an "unbiased" expert linked to the product, low standards of proof, etc). The approach is persuasive rather than critical. These infomercial-like elements reinforce Tufte's complaint that PowerPoint presentations have "an attitude of commercialism that turns everything into a sales pitch." ${ }^{22}$

Although librarians often see these elements in PowerPoint presentations, they don't often notice them. The repetition of these standard elements results in deeply uniform presentations and contributes to the perception by numerous respondents that "PowerPoint is boring."

\section{Colleague-Centered Presentations}

Knowledge lives in communities. Colleague-centered presentations tap into the community's collective experience and intelligence by proposing problems rather than providing solutions. Our vision of a preferred presentation at a professional conference is a Colleague-centered presentation. It reflects our belief that the collective experience and intelligence of the audience often exceeds that of a single or few presenters. For those considering presentations at library conferences, we offer the following guiding principles underlying Colleague-centered presentations:

1. Think of yourself as a facilitator rather than the speaker. Think of the program as a conversation. Consider those who have gathered together for the program as colleagues and contributors rather than the audience. As the facilitator, you will not be pouring wisdom and truth into a passive audience but coordinating discussion with active colleagues that have something to contribute to your ideas.

2. Design your program so it taps into and unleashes the collective intelligence of your colleagues. Although you can start your program by sharing your findings or business practices, after no longer than twenty minutes, involve your colleagues by posing problems and asking their advice rather than simply providing them with solutions. Note that the adult attention span is 20 minutes. ${ }^{23}$ The mismatch between the typical 60/90/120-minute program at a library conference and the 20-minute adult attention span suggests you should include your most important points in the first 20 minutes of your program.

3. Rather than delivering a predetermined, unidirectional monologue for the majority of the presentation, anticipate areas of interest and questions and build a presentation that is flexible enough to flow with collegial interest.

4. Look upon the presentation as a learning experience for your colleagues rather than a teaching opportunity for you.

5. Consider your presentation as an idea. The emergence and evolution of ideas is a social process. Presentations represent a stage of development in the life cycle of your ideas. Interaction with your colleagues during your presentation should enrich your ideas and provide you with some new insight that either reinforces or challenges your thoughts. In essence, your idea's life span should exceed your presentation. Depending on the life cycle of your idea, connection and engagement with colleagues during your presentation might lead to a reformulation of an idea that leads to an improved publication after the presentation or a change in the direction or implementation of a library service.

6. Imagine your presentation as a stepping stone for colleagues to read your handout (a position paper or essay written in a word-processing program that supplements or replaces your printed PowerPoint slides).

7. Remember that PowerPoint is only one element in a successful presentation experience. In addition to providing useful content to improve library services, part of your job as a conference presenter is to connect with your colleagues emotionally. Although people can be moved by presentation content, providing your colleagues with a voice and space to share their insights and problems often goes a long way toward creating a likeable and memorable learning experience.

\section{POWERPOINT'S CONTRIBUTION IN A COLLEAGUE-CENTERED PRESENTATION}

Through the use of evocative visual media and interactive tools, PowerPoint can be a tool to engage audiences. Rather than presenting at audiences with PowerPoint, it can help you hold conversations with colleagues. Using the guiding principles described above, we offer the following suggestions on how to use (and not use) Power- 
Point to help you connect with and engage your colleagues:

1. PowerPoint is a visual medium. "It lends itself to topics that are better explained graphically." ${ }^{24}$ Use it in that way. Think visually. Move toward a judicious mix of visuals such as photos, illustrations, diagrams, flowcharts, and video clips. Transform your words and stories into visuals and sounds. Use visuals and sounds to reinforce and add to your words rather than repeat them. ${ }^{25}$ To illustrate, if you are talking about student perceptions of plagiarism, instead of providing your colleagues with a slide containing a paragraph of text quoting a particular student or five bullet points of data, why not show several short video clips of students describing their perceptions? To ensure that your presentation does not become infomercial-like, make sure to include students that don't agree with the official association position, that don't simply echo dominant ideas, or that don't find your library services or resources helpful. Put another way, don't just select and reinforce your message by pointing to successes and positive feedback; make sure to include failures and negative feedback in your presentation. Another way to transform your text into visuals is to represent the emotional feeling of your message. Again drawing on the plagiarism theme, rather than a bulleted list of sentence fragments telling explaining plagiarism is a crime and that those guilty of it can face penalties, why not show a photo of someone cheating, a prison inmate, or someone being arrested and handcuffed to supplement your words during the talk?

2. Consider ways you can use PowerPoint to solicit your colleague's perceptions and experiences. For example, PowerPoint presentation consultant Cliff Atkinson demonstrates how one can use an evocative approach with PowerPoint. Rather than reading or describing the text on your slides, in the evocative approach you invite colleagues to contribute through speaking about visual images. ${ }^{26}$ For example, instead of reading through a list of six bullet points characterizing the behaviors of millennial students, show a simple slide featuring a photo of a millennial student on a blank background. The slide should contain no text. Ask the audience to describe the typical research behaviors of the student depicted in the slide. Ask them why and how they have arrived at these conclusions.

3. Design your presentation in fifteen- to twenty- minute sections with a change of mode and activity between each section. Use interactive tools such as clickers (audio response cards) to solicit your colleagues opinion and to refresh attention every ten minutes or so. For younger colleagues, consider using avatars and animation to introduce topics and interact with the audience. Like video clips, clickers, animation, and avatars should be used judiciously, or you run the risk of irritating your colleagues and distracting from your message. The challenge here is to develop effective questions that engage your colleagues, elicit their opinions, and help them reflect on the problem.

4. Develop a nonlinear presentation. Instead of reading though a sequential list of slides, create your presentation in modules or sections. Use triggers and hyperlinks to move seamlessly to topics of interest to your colleagues.

5. Use text sparingly. The more text you use, the more tempted you will be to read from the slides.

6. Don't try to fill your entire time with slides. Shorten your content, and if you are using slides primarily composed of text, keep the number of slides to about one for every five minutes of presentation. If your slides are primarily visuals, then you can show considerably more. When your slide is no longer useful, blank the screen by pressing the B key (for a black image) or the W key (for a white image) on the keyboard. Press the B or W key again to return to your slides.

7. Choose color combinations that contrast well and that convey the emotional mood you hope to communicate. We recommend a dark blue background with white or yellow text. Because projectors often display colors differently, test your completed slides with several projectors.

8. Make sure your font size is large enough to read. Paradi claims that "any font size less than 24 point is too small to read in most presentation situations." He suggests using 28- or 32-point size for most text and 36- to 44-point size for titles. ${ }^{27}$

9. Buy and use a remote control to advance your slides. Move around the room and talk with colleagues. Try to keep the room as light as possible without jeopardizing viewing of the screen content.

10. Provide a position paper or essay in wordprocessed document as a handout. Here you can use all the text and numbers you need to communicate your message.

11. Don't read your slides! 


\section{CONCLUSION}

Despite its prevalence at library conferences, the PowerPoint presentation is a misunderstood and underresearched form of communication. Consequently, many librarians have produced and viewed far too many unproductive PowerPoint presentations. People do not fly across the world to attend conferences to sit in a dark room and look at the back of someone's head while they read incomplete sentences on a projector screen. People attend conferences to share their insights, take part in conversations, contribute to the solutions to problems, and take information back to their library to improve services. If presenters choose to use PowerPoint, they should develop techniques to visualize their ideas and engage their colleagues using the tool. We hope our suggestions will help in the development of more interesting, understandable, enjoyable, and memorable learning experiences.

\section{References and Notes}

1. The authors presented a version of this paper and research findings at the 2007 LOEX Conference in San Diego, California, titled "Next Slide Please': An Analysis and Conversation on the Uses and Misuses of Microsoft PowerPoint at Library Instruction Conferences." The published proceeding for this conference offers a sample of the verbatim responses from the survey.

2. See Stephen Abram, "PowerPoint: Devil in a Red Dress," Information Outlook 8, no. 3 (2004): 27; Steven J. Bell, "End of PowerPoint Dependency Now!" American Libraries 35, no. 6 (2004): 56-59; Sharon Colvin, "How to Keep the Audience Awake and Learning," Information Outlook 11, no. 2 (2007): 24; and Michael Gorman, Our Own Selves: More Meditations for Librarians (Chicago: ALA, 2005).

3. Edward Tufte, The Cognitive Style of PowerPoint (Cheshire, Conn.: Graphics Pr., 2003): 4.

4. Gordon Shaw, Robert Brown, and Philip Bromiley, "Strategic Stories: How 3M is Rewriting Business Planning," Harvard Business Review 76, no.3 (1998): 42-44, quoted in Tufte, The Cognitive Style of PowerPoint, 4.

5. Catherine Adams, "PowerPoint, Habits of Mind, and Classroom Culture," Journal of Curriculum Studies 38 (2006): 389-411.

6. Stephen M. Kosslyn, Clear and to the Point: 8 Psychological Principles for Compelling PowerPoint Presentations (New York: Oxford Univ. Pr., 2007).

7. Dave Paradi, "Survey Shows How to Stop Annoying Audiences with Bad PowerPoint," www.thinkoutsidetheslide.com/articles/pptsurvey_article.htm (accessed
Jan. 5, 2007); and Dave Paradi "What Annoys Audiences about PowerPoint Presentations?" www.thinkoutsidetheslide.com/pptresults2005.htm (accessed Jan. 5, 2007).

8. Neil D. Fleming and Colleen Mills, "Not Another Inventory, Rather a Catalyst for Reflection," To Improve the Academy 11 (1992): 137-48.

9. Dave Paradi's Color Contrast Calculator is available online at www.thinkoutsidetheslide.com/colorcontrast.htm (accessed Jan. 5, 2007).

10. Tufte, The Cognitive Style of PowerPoint, 5.

11. Gordon Shaw, Robert Brown, and Philip Bromiley, "Strategic Stories: How 3M is Rewriting Business Planning," Havard Business Review 76, no. 3 (1998): 42, 44.

12. Tufte, The Cognitive Style of PowerPoint, 4.

13. Ibid., 6 .

14. StudioKSG, Kennedy School of Government, Harvard University, "Tips to Producing an Effective PowerPoint Presentation," www.ksg.harvard.edu/studioksg/ powerpointtips.htm (accessed Mar. 10, 2007).

15. Atul Chitnis, "Speaker Guide," http://linux-bangalore. org/2003/guides/speakers.php (accessed Apr. 20, 2007).

16. Dickinson College, Technology Services, "Presenting with PowerPoint: 10 Dos and Don'ts," http:// library.dickinson.edu/technology/Training/Tutorials/ MS2007/PP/dosdonts.pdf (accessed Apr. 10, 2007).

17. Princeton University Library Human Resources, "Library Excellence Toolkit: Presentation Skills," http://library.princeton.edu/hr/training/training_doc html (accessed Apr. 6, 2007).

18. Seth Godin, "Really Bad PowerPoint (and How to Avoid it)," www.sethgodin.com/freeprize/reallybad-1. pdf (accessed Mar. 15, 2007).

19. Corbin Ball, "Avoiding 'Death by PowerPoint,"' www. corbinball.com/articles/art-powerpoint.htm (accessed Apr. 2, 2007).

20. Geetesh Bajaj, "Choose the Right Colors in PowerPoint," Computer Companion (Spring 2006). www .computorcompanion.com/LPMArticle. asp? ID =262 (accessed Feb. 11, 2007).

21. Dave Paradi, "How to Avoid 'Death by PowerPoint,"' www.thinkoutsidetheslide.com/articles/avoid_death_ by_ppt.htm (accessed Jan. 5, 2007).

22. Tufte, The Cognitive Style of PowerPoint, 4.

23. Alex H. Johnstone and Frederick Percival, "Attention Breaks in Lectures," Education in Chemistry 13, no. 2 (1976): 49-50; and Joan Middendorf and Alan Kalish, "The 'Change-Up' in Lectures," National Teaching and Learning Forum 5, no. 2 (1996), www.ntlf.com/ html/pi/9601/articlel.htm (accessed July 10, 2007).

24. Karen Stein, "The Dos and Don'ts of PowerPoint Presentations," Journal of the American Dietetic Association 106, no. 11 (2006): 1745.

25. Godin, "Really Bad PowerPoint."

26. Cliff Atkinson, "Evocative Media," www.beyondbullets .com/2004/06/evocative_media.html (accessed Apr. 2, 2007).

27. Dave Paradi, "How to Avoid 'Death by PowerPoint." 